\title{
ORLANDO E MRS. DALLOWAY E A RECONFIGURAÇÃO DA NARRATIVA DE VIRGINIA WOOLF NA TELA
}

\begin{abstract}
Carlos Augusto Viana da Silva ${ }^{1}$
Resumo: Este artigo tem como principal objetivo analisar algumas marcas de reconfiguração das narrativas dos romances Mrs. Dalloway (1925) e Orlando (1928), de Virginia Woolf, em suas adaptações para o cinema. Considerando princípios teóricos sobre o romance moderno e a narrativa cinematográfica (BORDWELL, 1985; AUERBACH, 1998), descreveremos procedimentos tradutórios no processo de representação dos universos literários desses romances para as telas, bem como traços particulares de criação por parte das diretoras na construção das narrativas cinematográficas Mrs. Dalloway (1997), por Marleen Gorris, e Orlando (1992), por Sally Potter.
\end{abstract}

Palavras-chave: adaptação, cinema, narrativa

\section{ORLANDO AND MRS. DALLOWAY AND THE RECONFIGURATION OF VIRGINIA WOOLF'S NARRATIVE ON SCREEN}

\begin{abstract}
This paper has as the main objective to analyse some marks of narrative reconfiguration of the novels Mrs. Dalloway (1925), and Orlando (1928), by Virginia Woolf in their adaptations to the cinema. Considering some theoretical principles on modern novels and cinematographic narratives (BORDWELL, 1985; AUERBACH, 1998), we will describe some procedures of translation in the process of representation of the literary universes of these novels into screen, as particular traits of creation by the directors in the construction of the cinematographic narratives Mrs. Dalloway (1997), by Marleen Gorris, and Orlando(1992), by Sally Porter.
\end{abstract}

Keywords: adaptation, cinema, narrative

\footnotetext{
1 Professor Associado do Departamento de Estudos da Língua Inglesa, suas Literaturas e Tradução/Programa de Pós-Graduação em Letras, Universidade Federal do Ceará - UFC. Endereço Eletrônico: cafortal@hotmail.com
} 


\section{Introdução}

Os romances Mrs. Dalloway (1925) e Orlando (1928), da escritora inglesa Virginia Woolf, acentuam diferenças com relação à narrativa tradicional realista e naturalista, rompendo com os ditames de sua unidade estrutural. Enquanto as narrativas tradicionais estão mais preocupadas em contar ou descrever fatos de uma pretensa "realidade" externa, os romances de Woolf fazem um movimento contrário na medida em que o material mais importante para a tessitura narrativa são as conjecturas dos personagens, ou seja, a memória, as impressões, as divagações e os fluxos de consciência.

Para Lodge (1989, p.394), esse romance, que chamamos aqui de moderno, tem a proposta de fazer o leitor mergulhar num fluxo constante de experiência, o que o faz se familiarizar progressivamente com o processo de associação de impressões, ideias e memória. Assim, o enredo passa a não ser o mais relevante para o desenvolvimento de sua narrativa, que deixa de ser linear com final aberto ou ambíguo.

A tradução das narrativas supracitadas para o cinema empreende grande esforço criativo, pois se trata de universos literários complexos com estruturas narrativas particulares que desafiam o público receptor. Sally Potter e Marleen Gorris investiram na tarefa e adaptaram respectivamente para as telas Orlando (1992) e Mrs. Dalloway (1997). Neste artigo, descreveremos e analisaremos algumas estratégias de tradução por elas utilizadas na construção das narrativas no cinema, entendendo que as narrativas fílmicas, mesmo apresentando marcas próprias na reorganização das estruturas narrativas, e, assim, tornando-se mais convencionais com relações aos textos de partida, enfatizam para o espectador a complexidade temática dessas obras.

\section{0 estilo e a composição da narrativa cinematográfica}

Sabe-se que o cinema desenvolveu mecanismos autônomos de comunicação e garantiu o seu campo de delimitação dentro das artes modernas. O filme, enquanto produto desse campo, é um dispositivo de representação, uma vez que possui mecanismos próprios de organização dos 
espaços e dos papeis discursivos que desempenha como texto produtor de significado.

Bordwell (1985, p. 50), na tentativa de definir uma especificidade e autonomia dos materiais e dos procedimentos de operação do cinema, aponta o estilo como um elemento importante para a análise da narrativa fílmica. Esse elemento, na sua visão, está ligado ao uso sistemático dos recursos cinematográficos de acordo com os princípios de organização da narrativa, por meio de interação de vários modos com o enredo. Se, por um lado, a narrativa de um filme consiste de um padrão particular de eventos e pode ser descrita por procedimentos que envolvem ações, cenas, articulação de tempo e espaço, por outro, o mesmo filme pode ser descrito do ponto de vista da aplicação das técnicas cinematográficas como a iluminação, o som, a edição etc. O primeiro caso relaciona-se ao enredo; e o segundo, ao estilo. Para Bordwell (1985, p. 51), esses dois sistemas coexistem na narrativa fílmica porque ambos tratam de fenômenos diferentes no processo, ou seja, o enredo diz respeito ao filme como um processo "dramatúrgico" e o estilo como um processo técnico.

Os conceitos em questão são interessantes para a análise fílmica porque permitem que seja feita a distinção entre formatos narrativos diferentes, por meio da parametrização de configuração de padrões regulares de construção de narrativas na apresentação da história e da manipulação das possibilidades de desenvolvimento de enredos e marcação de estilo.

Ao apresentar a casualidade como o princípio básico de construção da narrativa cinematográfica clássica americana, Bordwell (1985, p. 157) descreve alguns elementos norteadores de sua composição. Para o autor, o enredo desse tipo de narrativa representa ordem, frequência e duração dos eventos da história de forma que saliente as relações causais. Assim o enredo apresenta uma estrutura causal dupla, ou seja, duas linhas: uma envolvendo um romance heterossexual (rapaz/moça, esposo/esposa); a outra envolvendo outra esfera como trabalho, guerra, uma missão ou busca, outras relações pessoais. Cada uma dessas linhas, reforça Bordwell, terá um objetivo, obstáculos e um clímax. Podemos dizer então que a natureza estrutural dessa narrativa está subordinada à clareza, à homogeneidade, à linearidade, à coerência e ao impacto dramático. Existem situações de confronto e conflito, 
mas o desenvolvimento narrativo leva ao espectador as respostas às questões postas no filme.

A narrativa cinematográfica moderna, aquela comum ao cinema de arte europeu cujo modelo se opõe à narrativa clássica americana, por outro lado, toma uma nova posição em relação a ela, consolidando um novo modelo. Caracteriza-se por ser mais fluida, menos ligada organicamente e menos dramatizada. Apresenta lacunas ou questões não resolvidas com finais às vezes abertos ou ambíguos (VANOYE; GOLIOT-LÉTÉ, 1994, p. 35-36).

Quanto à construção dos personagens, a narrativa moderna apresenta uma menor nitidez no seu delineamento. Estes são colocados na narrativa muitas vezes em crise (crise de casais, crise psicológica), deixando clara uma propensão a uma confusão das fronteiras entre objetividade e subjetividade e tendência à reflexividade. Nesse sentido, as formas de manipulação do material narrativo reforçam a presença de autoria na construção do filme por meio das marcas estilísticas sobre os personagens e a história.

Brito (1996, p. 197) afirma que o sistema abstrato que sustenta o modelo de cinema de arte europeu tem uma pretensão de ser antissistema, porque, diante dele, o espectador depara-se com novas construções semióticas, códigos e signos e mais ainda com suas virtuais combinações. Assim, a narrativa moderna contrapõe-se ao modelo clássico passando a ser incomunicável (ou pelo menos de comunicabilidade problemática), imprevisível (o espectador nunca prevê a conclusão) e aberta (sua significação depende do investimento semiótico por parte do espectador para preencher os vazios semânticos da forma que lhe for conveniente).

A tendência de redimensionamento da narrativa cinematográfica clássica para o modelo antissistêmico do cinema de arte europeu foi inspirada, na visão de Brito (1996, p. 197), na proposta de desestruturação da narrativa literária tradicional, empreendida por alguns escritores do século passado, a começar por James Joyce. Nesse contexto, Virginia Woolf se insere e as suas narrativas são discutidas por críticos, tais como Silva (1988), Auerbach (1998), Humphrey (1972) e outros, como ícone vanguardista em relação às narrativas tradicionais, com grande impacto no cenário da produção literária moderna. 
O padrão narrativo de seus romances redimensiona características estruturais do romance tradicional pelo uso da experimentação e da consolidação de um novo processo de escrita em que se apresenta o "reflexo múltiplo da consciência", conforme reforça Auerbach (1998, p.495), o que traz para diretores grandes desafios em processos de transmutação dessas obras para outros meios de linguagem.

\section{A narrativa de virginia woolf}

Os romances Mrs. Dallowaye Orlando conferiram a Virginia Woolf a afirmação e o domínio de uma nova técnica de escrita, o fluxo de consciência. Assim, a autora e outros escritores contribuíram para o surgimento de um novo tipo de romance. Utilizando Mrs. Dalloway como exemplo, podemos dizer que seu construto narrativo particular custou a Woolf, por um lado, um enorme esforço mental e um grande desafio, como ela própria assinala em seu diário: "One feels about in a state of misery - indeed I made up my mind one night to abandon the book - $\&$ then one touches the hidden spring" (WOOLF apud BELL, 1981, p. 272); e, por outro, uma visibilidade cada vez maior pela crítica e seu estabelecimento no cânone literário inglês.

Publicado em 1925, este romance, que é o quarto de Woolf, representa, para o conjunto da obra da autora, a afirmação da nova técnica de escrita. A narrativa é de caráter experimental, com uma ação de natureza reduzida, o que confere ao livro um título de romance impressionista, conforme classificou Silva (1988, p. 734), não por pertencer ao movimento impressionista, mas por descrever impressões dos personagens e não as coisas em si.

A história de Mrs. Dalloway se passa em um único dia na vida da personagem Clarissa Dalloway, na cidade de Londres, em junho de 1923. Nesse dia, a personagem revê e reflete sobre a sua vida, enquanto prepara mais uma festa. A “ação" narrativa se desenvolve, principalmente, pelas divagações dos personagens, por meio dos constantes deslocamentos temporais entre os fatos externos e suas realidades internas. Esses fatos em si são triviais, porque o mais importante para a confecção do construto narrativo é a apreensão do material psicológico das mentes e não dos fatos. Rompe então com os padrões 
do romance tradicional, transformando-se num projeto narrativo de vanguarda no cenário literário moderno.

Seu tecido narrativo se desenvolve com base em um único ponto: a realização de uma festa. O fio condutor do processo se estende dos preparativos até a realização de um evento que representa não somente um único dia na vida de Clarissa Dalloway, personagem central, mas o resgate de toda uma existência. A personagem anda pela cidade para comprar flores, organiza a casa para receber convidados e recebe a visita de Peter Walsh, seu pretendente quando ela era ainda jovem.

Há, no romance, descrição constante dos momentos de experimentação de Clarissa. É o caso dessa passagem em que Clarissa caminha e observa a cidade:

\footnotetext{
Mrs. Dalloway said she would buy the flowers herself. For Lucy had her work cut out for her. The doors would be taken off their hinges; Rumpelmayer's men were coming. And then, thought Clarissa Dalloway, what a morning - fresh as if issued to children on a beach (WOOLF, 1976, p. 7).
}

And there the motor car stood, with drawn blinds, and upon them a curious pattern like a tree, Septimus thought, and this gradual drawing together of everything to one centre before his eyes, as if some horror had come almost to the surface and was about to burst into flames, terrified him. The world wavered and quivered and threatened to burst into flames (WOOLF, 1976, p. 19).

As descrições acima têm como principal função na narrativa mostrar êxtase e deslumbramento por uma situação aparentemente trivial, mas que representa para a personagem a própria dinâmica da vida. Entretanto, tal dinâmica é interrompida na sua totalidade pela presença da morte, que ecoa sobre a vida, encarnada na figura do personagem Septimus, um neurótico de guerra, que se suicida, e Clarissa recebe a notícia dessa tragédia durante a festa. Assim, a narrativa estabelece um contraponto importante em que, de um lado, Clarissa representa, essencialmente, a ideia de plenitude e vida; enquanto Septimus, do outro, isolamento e morte. 
Mesmo com o emprego de recursos inovadores de escrita em sua elaboração, o romance apresenta um enredo tecnicamente definido. Isso se dá pela presença de uma cronologia aparente, ou seja, no romance, tudo se passa em algumas horas de um dia de junho na cidade de Londres. Nessas poucas horas em que o leitor mergulha no universo de Clarissa Dalloway, a ideia de tempo é sempre ressaltada e o espaço é a priori delimitado. O espaço real é Londres e o tempo cronológico é delimitado por um dia, marcado pelas batidas do Big Ben. No entanto, essas restrições são logo superadas porque, como os acontecimentos são triviais e não há ação propriamente dita, logo infere-se que o que importa é a penetração no universo interior dos personagens.

O romance Orlandoé o sexto da autora e foi publicado em 1928, com subtítulo "uma biografia" e uma dedicatória a Vita Sackville-West, uma aristocrata da sociedade londrina. A narrativa mostra a trajetória do personagem principal Orlando dos seus dezesseis anos de idade, no final do século XVI, até os trinta e seis no século XX. O narrador, ou o biógrafo, conta a história desse personagem, utilizando uma sequência cronológica de fatos que ocorrem ao longo dos séculos. Com o passar do tempo, o comportamento dele se altera, bem como seu gênero (inicia a narrativa como homem e termina como mulher).

A narrativa se desenvolve a partir de situações reais com referências de espaço da Inglaterra, por exemplo, a mansão do personagem Orlando que faz referência ao castelo Knole da família Sackville, no primeiro capítulo, bem como a presença de momentos históricos e situações que a/o personagem enfrenta ao longo de sua trajetória.

Ao discutir a mansão de Orlando como ponto de referência espacial, Anastácio (2006, p. 24) enfatiza a ideia de que o espaço de propriedade guarda toda a memória da narrativa em que passado e presente se fundem na consciência do narrador. Nesse sentido, o romance apresenta uma descrição mais realista, se comparado ao romance Mrs. Dalloway, mas, mesmo assim, tem estrutura narrativa inovadora pelo fato de o foco de interesse recair mais sobre a identidade fluida do protagonista e suas percepções, por vezes fantasiosas, do que sobre as situações apresentadas.

Tais percepções também se manifestam através de temas complexos que perpassam toda a narrativa. Entre várias discussões 
recorrentes na obra, podemos citar historiografia literária, crítica social, embaralhamento de fronteiras entre fatos históricos e ficção, e androginia. Merece destaque o tema da androginia pelo impacto que tem na própria concepção da narrativa em que jogos de simulações se estabelecem na dinâmica do próprio enredo. Se considerarmos os personagens, percebemos que vários deles apresentam características ambíguas de gênero: Orlando, Arquiduquesa-Arquiduque, Shelmerdine. Neles, podemos perceber duplicidade e fluidez nos comportamentos e inversão do padrão tradicional de construção de identidade fixa. No caso específico de Orlando, ele inicia a narrativa como homem e, em seguida, torna-se mulher, vivenciando, ao longo de sua existência, a experimentação de universos distintos, tais como a desilusão amorosa com Sasha, sua estada em Constantinopla como embaixador extraordinário do rei, e as juras de amor por parte do arquiduque Harry, já como mulher etc. É através dessa experimentação que processos de subjetivação se intensificam e apontam para a discussão de um novo conceito de sujeito que se afasta de dicotomias de gêneros (masculino e feminino), para uma visão mais plural e híbrida, como é reforçada no romance:

The difference between the sexes is, happily, one of great profundity. Clothes are but a symbol of something hid deep beneath. It was a change in Orlando herself that dictated her choice of a woman's dress and of a woman's sex. [...] For here again, we have to come to a dilemma. Different though the sexes are, they intermix. In every human being a vacillation from one sex to the other takes place, and often it is only the clothes that keep the male and female likeness, while underneath the sex is the very opposite of what it is above. (WOOLF, 1993, p. 132-133).

Como podemos perceber, sinaliza-se uma visão profunda da sexualidade humana, desconstruindo parâmetros sociais e, consequentemente, sugere o rompimento de padrões preestabelecidos de escrita em que geralmente categorias narrativas bem definidas são empregadas, o que exige dos leitores uma nova postura de leitura.

No que diz respeito à estrutura temporal, a narrativa de Orlando difere da estrutura de outros romances de Woolf, por apresentar uma sequência cronológica em que vários fatos são registrados para que o leitor se 
situe. Mas, mesmo seguindo uma estrutura mais linear com relação a outros romances, a autora apresenta na tessitura do texto aspectos impressionistas que se mostram através de aspectos, tais como descrições pictóricas, fantasia, sátira, crítica social e o próprio questionamento sobre a relação do indivíduo com o fluxo da história e a História da Inglaterra.

Embora não seja enquadrado na lista dos projetos narrativos mais vanguardistas de Woolf, por apresentar situações e fatos com andamento de certa forma linear, o romance enfoca também o mundo interior de suas personagens, registrando o fluxo das ideias e percepções que eles têm da "realidade".

Ao serem traduzidos para as telas, os romances Mrs. Dalloway e Orlando foram recriados, e suas estruturas narrativas ressignificadas, assumindo um novo padrão narrativo nos novos contextos de chegada. Entretanto, podemos dizer que o processo de recriação não implica necessariamente um afastamento completo dos universos literários em questão, pois existem diálogos no nível temático.

\section{Os filmes e as marcas de reconfiguração da narrativa de woolf na tela}

As adaptações cinematográficas Orlando (1992), por Sally Potter, e Mrs. Dalloway (1992), por Marleen Gorris, estabelecem um diálogo com os respectivos romances de Virginia Woolf no nível mais temático, pois no nível da estruturação do construto narrativo, apresentam traços particulares de criação. Dentre as principais estratégias de tradução utilizadas para marcar essas novas configurações, podemos destacar, pelo menos duas, em Mrs. Dalloway: a inserção de tom dramático à narrativa e a reorganização do arranjo narrativo no sentido de dar maior linearidade aos eventos.

O caráter mais dramático conferido à narrativa de Gorris é sustentado, principalmente, pelo uso constante da técnica de close-upem que, em várias situações, enfatizam-se a expressão e os gestos dos atores/atrizes, com especial destaque em momentos em que suas intimidades são reveladas, tendo como efeito imediato, a aproximação do espectador com os momentos de vida dos personagens. Ao discutir a técnica, Balázs (1992, p. 261) afirma que close-ups são sempre revelações dramáticas do que está realmente 
acontecendo além das aparências superficiais, expressando a sensibilidade poética do diretor. No filme de Gorris, a técnica aparece desde o início da narrativa quando mostra a cena da morte de Evans, amigo de Septimus (Rupert Graves), e sua reação diante do fato, e reforça o primeiro dos dois grandes argumentos da narrativa, os efeitos da guerra.

O segundo argumento se fortalece a partir da cena em questão. Do espaço da trincheira e do horror, por meio de um corte, há a transferência da face de Septimus para Clarissa (Vanessa Redgrave), no espaço confortável do seu quarto. A câmara se movimenta lentamente até enquadrá-la num plano americano, diante do espelho. Clarissa está imersa em suas reflexões, que são repassadas para o espectador por meio da narração em voice-over. Embora apareça longo no início do filme, esta técnica não é frequente, ao longo da narrativa, pois a presença de diálogos é mais acentuada, bem como a presença de situações mais dramáticas na tela, o que contribui, na nossa visão, para estabelecer marcas de leitura da diretora no filme.

$\mathrm{O}$ foco na personagem Clarissa e nos seus pensamentos dão à narrativa um tom nostálgico, sugerindo lamento e saudosismo com relação ao seu passado. Esse tom é reforçado também pela inserção da música que é introduzida mesmo antes de a personagem aparecer na tela. A partir de então, a música passa a ser constante e funciona como elemento de captação dos momentos de intimidade da personagem, contribuindo para dar dramaticidade a esses momentos.

Outro aspecto importante que reforça o tom da narrativa desde seu início é um movimento lento da câmera em direção a Clarissa até focalizá-la diante do espelho. Através do espelho, o espectador se depara com um símbolo interessante que traduz a ideia de introspecção, do olhar da personagem para dentro de si, o que ocorrerá ao longo de um dia em sua vida. Isso ocorre porque o espelho, enquanto objeto, emoldura o processo de reflexão vivenciado pelos personagens, ao longo da narrativa, e confunde-se com o próprio objeto do desenvolvimento narrativo, como reforça Harrington (1978, p. 149), o símbolo evoca uma rede de significados interrelacionados.

Esses procedimentos ressaltam a interferência do estilo individual da diretora que exerce influência no processo, conforme ela mesma assinala ao ser entrevistada por Worsdale: 
Anyway, I make the films I want to make and the audience will see what they do. If they don't like it, well that's okay. If they do, then great. But, I think you should at least allow the artist the freedom of speech, to do what she or he wants to do (GORRIS apud WORSDALE, 1998, p. 3).

A fala de Gorris é esclarecedora quanto à ideia pressuposta de certa "autonomia", por parte do diretor no trabalho que se propõe a realizar. E, assim, explicam-se algumas de suas escolhas ao construir a narrativa de Mrs. Dalloway.

Outro ponto interessante a se considerar é o fato de Gorris dar ao diretor o estatuto de artista, ou seja, alguém que cria. Partindo desse pressuposto, ela se isenta de um compromisso necessário com o texto de Woolf, e corrobora uma discussão importante para os estudos da tradução, que é a questão da visibilidade do tradutor.

Nesse sentido, a nova configuração narrativa trazida para a tela evidencia relação com o texto de Woolf, e constitui-se narrativa significativa, uma vez que, mesmo reforçando traços particulares de leitura de Gorris, assegura para o espectador imagens importantes do texto adaptado.

O filme Orlando, assim como Mrs. Dalloway, traz marcas próprias no seu processo de criação, reforçando o caráter de linearidade. Similar ao romance de Woolf, apresenta uma sequência de eventos para situar o espectador com relação aos quatrocentos anos de história da Inglaterra em que o personagem Orlando vive. Mas, em outra perspectiva, estabelece uma divisão temática na narrativa em que, além das marcas temporais mostradas na tela, também são enfatizadas as grandes questões abordadas em cada período. Vejamos:

\author{
Sequência de abertura \\ 1600 Death-morte \\ 1610 Love- amor \\ 1650- Poetry- poesia \\ 1700- Politics - política \\ 1750- Society - sociedade \\ 1850- Sex - sexo \\ Birth-nascimento
}


Sabemos que a discussão acerca desses temas, no romance, é recorrente, mas a forma de apresentação é diferente. Ou seja, a discussão sobre os temas é diluída, ao longo da narrativa, e assim o leitor entra em contato com fatos relacionados ao universo dos personagens e aos poucos vai extraindo elementos fundamentais para a apreensão da complexidade envolvida na apresentação desses temas, uma vez que misturam-se, nesse construto, elementos que dialogam com a História, a memória, a realidade e a própria ficção. No filme, até pelas limitações do próprio meio, há uma inversão dessa lógica na maneira de lidar como esse material narrativo, ao optar por uma segmentação de blocos narrativos, utilizando o recurso da pontuação como forma de estabelecer a subdivisão desses blocos. Como resultado, apresenta-se para o espectador maior direcionamento das questões, já que aparecem na tela referências temporais, associando cada período a um tema.

Outra estratégia importante para a consolidação dessa nova organização da narrativa do filme foi o uso recorrente de close-up que, assim como corre no filme de Gorris, a técnica é reforçada logo no início no filme de Potter. Um exemplo bastante ilustrativo disso é a primeira cena em que Orlando (Tilda Swinton) se apresenta para o espectador, com voz feminina através de narração em voice-over. Na cena, Orlando se movimenta próxima a uma árvore, que pode ser vista como referência ao carvalho, árvore símbolo de resistência e longevidade, muito presente no romance, enquanto caminha e lê, o que seriam informações sobre ele próprio. Nesse momento a presença da árvore e as descrições do personagem apresentadas por ele mesmo trazem referências importantes do romance, no sentido de introduzir dados sobre a subjetividade do personagem e seu contexto social. Vejamos as primeiras linhas da narrativa do livro:

He - for there could be no doubt of his sex, though the fashion of the time did something to disguise it - was in the act of slicing at the head of Moor which swung from the rafters. It was the color of an old football, and more or less the shape of one, save for the sunken cheeks and a strand or two of coarse, dry hair, like the hair on a cocoanut. (WOOLF, 1993, p. 11). 
Esse texto introdutório do romance é mostrado na tela por meio da leitura que Orlando faz. Enquanto o espectador acompanha as imagens e ouve o texto, a leitura é interrompida abruptamente pelo próprio personagem que, ao olhar diretamente para a câmera, identifica-se, reforçando o fato de que a descrição em questão a ele se refere. Então, o personagem é mostrado em close-up, como uma forma de aproximação do público, que é desafiado a fazer conexões entre o que dito e o que é mostrado na tela sobre sua identidade, bem como sua própria intimidade.

Como podemos perceber, o início da narrativa fílmica faz referência direta ao texto de Woolf, mas, ao mesmo tempo, enfatiza traços particulares de sua construção. O personagem Orlando de Woolf, mesmo se transformando em mulher, ao longo do romance, no início do livro, é descrito como homem; o personagem de Potter, em outra perspectiva, sugere ambiguidade de gênero, já por ser interpretado por uma atriz. A representação do personagem por uma mulher gera um efeito bastante peculiar, logo no início da narrativa, que é a sugestão de uma reflexão atualizada sobre as novas discussões que tratam da complexidade e da fluidez das identidades, o que caracteriza o sujeito pós-moderno e sua fragmentação, nos termos de Hall (1998, p. 10). Neste caso, a ambiguidade de gênero do personagem é reforçada, bem como a natureza de sua identidade contraditória e não fixa. Assim, a diretora parece iniciar o texto cinematográfico, sinalizando para o espectador questões fundamentais do romance, mesmo que, para isso, tenha como princípio importante, a reorganização desse universo literário.

Ao discutirem o contato direto e intenso do personagem com o espectador, Higgins e Leps (2000, p. 24) afirmam que tal procedimento tornase importante para o desenvolvimento da narrativa por pelo menos dois motivos: pontua momentos-chave da narrativa e manifesta ironia no texto de Potter. Concordamos com essa visão e acrescentaríamos que esse procedimento pode ser visto ainda como uma tentativa de problematizar também com certo tom de ironia a discussão sobre literatura e gênero feita no romance, bem como uma forma de lidar com a técnica do fluxo da consciência presente na escrita de Virginia Woolf. A própria diretora chega a se posicionar sobre a questão: 
[...] Tentei escrever o roteiro todo em verso, até usar uma espécie de voiceover interior. E, finalmente, com a ajuda de Tilda Swinton, resolvi incluir as maneiras de Orlando olhar e se dirigir à câmera. Eu queria converter o engenho literário de Virginia Woolf em humor cinemático. (POTTER apud ANASTÁCIO, 2003, p.110).

Observa-se que a diretora buscou, através da utilização da técnica cinematográfica, que implica numa maior aproximação do personagem com o público, ressaltar sutilezas do texto de partida, no sentido de causar no espectador uma reação de estimular uma postura desafiadora de leitura do texto, como acontece com o leitor ao se deparar com o texto de Woolf.

A nova forma de estruturação das narrativas adaptadas traz desdobramentos interessantes quanto ao seu funcionamento e ao efeito por elas provocado na recepção do universo literário de Woolf nos novos contextos. Considerando que existem diferentes tipos de espectadores dessas adaptações, podemos imaginar três prováveis públicos receptores: o público leitor das obras de partidas; os que não leram essas obras, mas já leram alguma de suas reescrituras, tais como resenhas críticas, resumos, coletâneas literárias, ou até mesmo traduções em línguas estrangeiras, e têm uma ideia da posição dos textos de Woolf em relação ao cânone literário moderno; e, por último, mas não menos importante, aqueles que não conhecem nada a respeito da autora. No primeiro caso, encontram-se os leitores mais especializados, capazes de opinar e até julgar a "qualidade estética" das adaptações das obras. No segundo, estariam aqueles que já têm uma ideia do que seja o universo literário de Woolf e vêem nos filmes objetos de melhor visualização desse universo. E, no terceiro caso, estariam aqueles que estão sendo submetidos a esse universo por meio dessas adaptações pela primeira vez. Assim, mesmo que assumam posturas diferentes de leituras, nos três casos, os espectadores das adaptações em questão se deparam com imagens de "originais", ou seja, marcas particulares de leituras que refletem traços da poética de criação das diretoras. E, através dessas imagens, essas adaptações estabelecem diálogo com textos de grande prestígio literário da tradição ocidental. 


\section{Considerações finais}

Ao apresentarmos, ao longo dessa discussão, alguns aspectos sobre a construção narrativa das adaptações cinematográficas dos romances Mrs. Dalloway e Orlando, de Virginia Woolf, por Marleen Gorris e Sally Potter respectivamente, pudemos mostrar que tais narrativas foram redimensionadas, apresentam configurações particulares, na sua composição, estabelecendo marcas estruturais próprias no novo meio de linguagem. A reorganização linear de eventos em ambos os filmes, e a inserção de um caráter mais dramático em Mrs. Dalloway, por exemplo, podem ser vistas como estratégias importantes na elaboração desses novos formatos que as narrativas adaptadas assumem na tela.

Dessa forma, observam-se, nessas narrativas fílmicas, marcas que reforçam evidências de representação de uma Virginia Woolf cinematográfica, pelos traços peculiares que se manifestam através de uma construção narrativa mais convencional. E, mesmo reconhecendo a nova dimensão narrativa dada aos textos, não podemos também deixar de reconhecer que os filmes apresentam elementos importantes dos universos literários da autora, problematizando temas fundamentais desses universos para o espectador.

\section{Referências}

ANASTÁCIO, S. M. G. A criação de Orlando e sua adaptação fílmica. Salvador: Edufba, 2006.

AUERBACH, E. A meia marrom In: Mimesis. a representação da realidade na literatura universal. 4. ed. São Paulo: Perspectiva, 1998. p. 471-498.

BELL, A. O. The diary of Virginia Woolf. London: Peguin Books, 1981.

BALÁZ, B. The close-up. In: MAST, G. et al. Film theory and criticism. Fourth Edition, New York: Oxford University Press, 1992. p. 260-267.

BORDWELL, D. Narration in the fiction film. Wisconsin: The University of Wisconsin Press, 1985.

BRITO, J. B. Imagens amadas. São Paulo: Ateliê Editorial, 1995. 
HIGGINS, L.; LEPS, M. C. Mrs. Dalloway and Orlando: the subject of Time and Generic Transactions. In: CARTMELL, D. et al (Ed.). Classics in film and fiction. London-Sterlin, Virginia: Pluto Press, v. 5, 2000. p. 116-136.

HARRINGTON, J. The rhetoric of film. Massachusetts: University of Massachusetts, 1978.

HALL, S. A identidade cultural na pós-modernidade. Trad. Tomaz Tadeu da Silva e Guacira Lopes Louro. 2. ed. Rio de Janeiro: DP\&A, 1998.

HUMPHREY, R. Stream of consciousness in the modern novel. Berkeley, Los Angeles, London: University of California Press, 1972.

LODGE, D. A linguagem da ficção modernista: metáfora e metonímia. In: Modernismo: guia geral 1890 - 1930. São Paulo: Cia das Letras, 1989. p. 394-407.

MRS. DALLOWAY. Direção de Marleen Gorris. USA/UK/Netherland: Casablanca Filmes, 1997. [DVD] (100 min), Ntsc, son., color, Legendado, Port.

ORLANDO. Direção de Sally Potter. UK: Sony Pictures Classics, 1992 [DVD] (93 min), Ntsc, son. Color, Legendado, Port..

SILVA, V. M. de A. Teoria da literatura. 8. ed. Coimbra: Livraria Almedina, 1988.

VANOYE, F.; GOLIOT-LÉTÉ, A. Ensaio sobre a análise fílmica. Trad. Marina Appenzzeller. Campinas: Papirus, 1994.

WOOLF, Virginia. Mrs. Dalloway. London: Grafton Books, 1976.

WOOLF, Virginia. Orlando. London: Peguin books, 1993.

WORSDALE, A. A woman for all women. Za@PLAY -FILM, [s.l.], Julho 98. Disponível em:< http://www.mg.co.za/mg/art/film/1907/980702gorris.html>. Acesso em: 4 de Abr. 2002.

Recebido em 6 de março de 2017.

Aceito em 25 de maio de 2017. 